\title{
Corrigendum: DNA methylation dynamics in health and disease
}

Yehudit Bergman \& Howard Cedar

Nat. Struct. Mol. Biol. 20, 274-281 (2013); published online 5 March 2013; corrected after print 5 June 2013

In the version of this article initially published, on p. 274, the sentence: "One key factor appears to be ZFP57 (also known as KAP1)..." should have read: "One key factor appears to be the ZFP57-KAP1 complex...." KAP1 is a ZFP57-binding partner. The error has been corrected in the HTML and PDF versions of the article.

\section{Erratum: Molecular determinants of nucleosome retention at $\mathrm{CpG}$-rich sequences in mouse spermatozoa}

Serap Erkek, Mizue Hisano, Ching-Yeu Liang, Mark Gill, Rabih Murr, Jürgen Dieker, Dirk Schübeler, Johan van der Vlag, Michael B Stadler \& Antoine H F M Peters

Nat. Struct. Mol. Biol. 20, 868-875 (2013); published online 16 June 2013; corrected after print 12 July 2013

In the version of this article initially published, the parentheses in Figure 2a denoting noninclusive endpoints in ranges had not been indicated. The error has been corrected in the HTML and PDF versions of the article.

\section{Erratum: Activating silent Argonautes}

\section{Mary Anne Kidwell \& Jennifer A Doudna}

Nat. Struct. Mol. Biol. 20, 769-771 (2013); published online 3 July 2013; corrected after print 12 July 2013

In the version of this article initially published, in Figure 2 the asterisks representing mutations to the PIWI domain that turn Argonaute into an active enzyme should have been colored red. The error has been corrected in the HTML and PDF versions of the article.

\section{Erratum: Conformational dynamics of STIM1 activation}

Stefan Feske \& Murali Prakriya

Nat. Struct. Mol. Biol. 20, 918-919 (2013); published online 5 August 2013; corrected after print 23 August 2013

In the version of this article initially published, "Lys 251 " was incorrectly substituted for "Leu251" in Figure 1 and in the text. The error has been corrected in the HTML and PDF versions of the article. 